\title{
Effect of Marital Status on Depression and Mortality among Patients with Chronic Kidney Disease from National Health and Nutrition Examination Survey 2005-2014
}

\author{
Zu-feng Wang Yi-chun Cheng Nan-Hui Zhang Ran Luo Kang-lin Guo \\ Shu-Wang Ge Gang Xu
}

Division of Internal Medicine, Department of Nephrology, Tongji Hospital, Tongji Medical College, Huazhong University of Science and Technology, Wuhan, China

\section{Keywords \\ Chronic kidney disease · Marital status · Depression · Mortality}

\begin{abstract}
Background: The relationship between marital status and CKD is rarely studied. We aimed to explore the effect of marital status on the depression and mortality of patients with CKD. Methods: The data sources came from the NHANES database during 2005-2014 and 3,865 participants were included in this study. We used logistic regression models to examine the relationship between marital status and depression of CKD patients. The Cox proportional hazard models were used to evaluate the association between marital status and mortality of CKD patients. Results: In terms of depression in CKD patients, unmarried patients had a worse situation than married patients. Meanwhile, after adjusting the covariables, unmarried patients had increased risk of depression (OR $=1.26,95 \% \mathrm{Cl}: 1.01-1.57)$ compared with married CKD patients, especially in males (OR $=1.45,95 \% \mathrm{Cl}: 1.02-$ 2.06) and patients with more than college education level $(\mathrm{OR}=12.4,95 \% \mathrm{Cl}: 3.75-41.02)$. There was a significant relationship between marital status and mortality of general CKD patients $(\mathrm{HR}=1.36,95 \% \mathrm{Cl}: 1.17-1.58)$. Moreover, mar-
\end{abstract}

riage showed a protective effect against death among male patients, patients with school graduate or less and more than college educational level, patients with high income, and patients in different estimated glomerular filtration rate groups. Conclusions: The use of large numbers of participants has revealed the effect of marital status on CKD patients. Unmarried ones had a higher risk of depression than married ones among CKD patients. Meanwhile, the risk of death was higher in unmarried ones than married ones among CKD patients in this study.

(C) 2021 The Author(s)

Published by S. Karger AG, Basel

\section{Introduction}

The prevalence of $\mathrm{CKD}$ is estimated to be $8-16 \%$ worldwide [1], and CKD affected $15 \%$ of the US population in 2018 [2]. Patients with CKD have a higher risk of substantial complications, including depression [3], cardiovascular disease [4], and death [5]. In addition to the treatment measures, many societal factors may also influence the mental health and mortality of CKD patients [6].

Zu-feng Wang and Yi-chun Cheng contributed equally to this work. Shu-Wang Ge and Gang Xu contributed equally to this work. karger@karger.com www.karger.com/kdd

Karger $\stackrel{\text { ' }}{5}$

BOPEN ACCESS
(C) 2021 The Author(s)

Published by S. Karger AG, Basel

This is an Open Access article licensed under the Creative Commons Attribution-NonCommercial-4.0 International License (CC BY-NC) (http://www.karger.com/Services/OpenAccessLicense), applicable to the online version of the article only. Usage and distribution for commercial purposes requires written permission.
Correspondence to:

Shu-Wang Ge, geshuwang@tjh.tjmu.edu.cn

Gang Xu, xugang@tjh.tjmu.edu.cn 


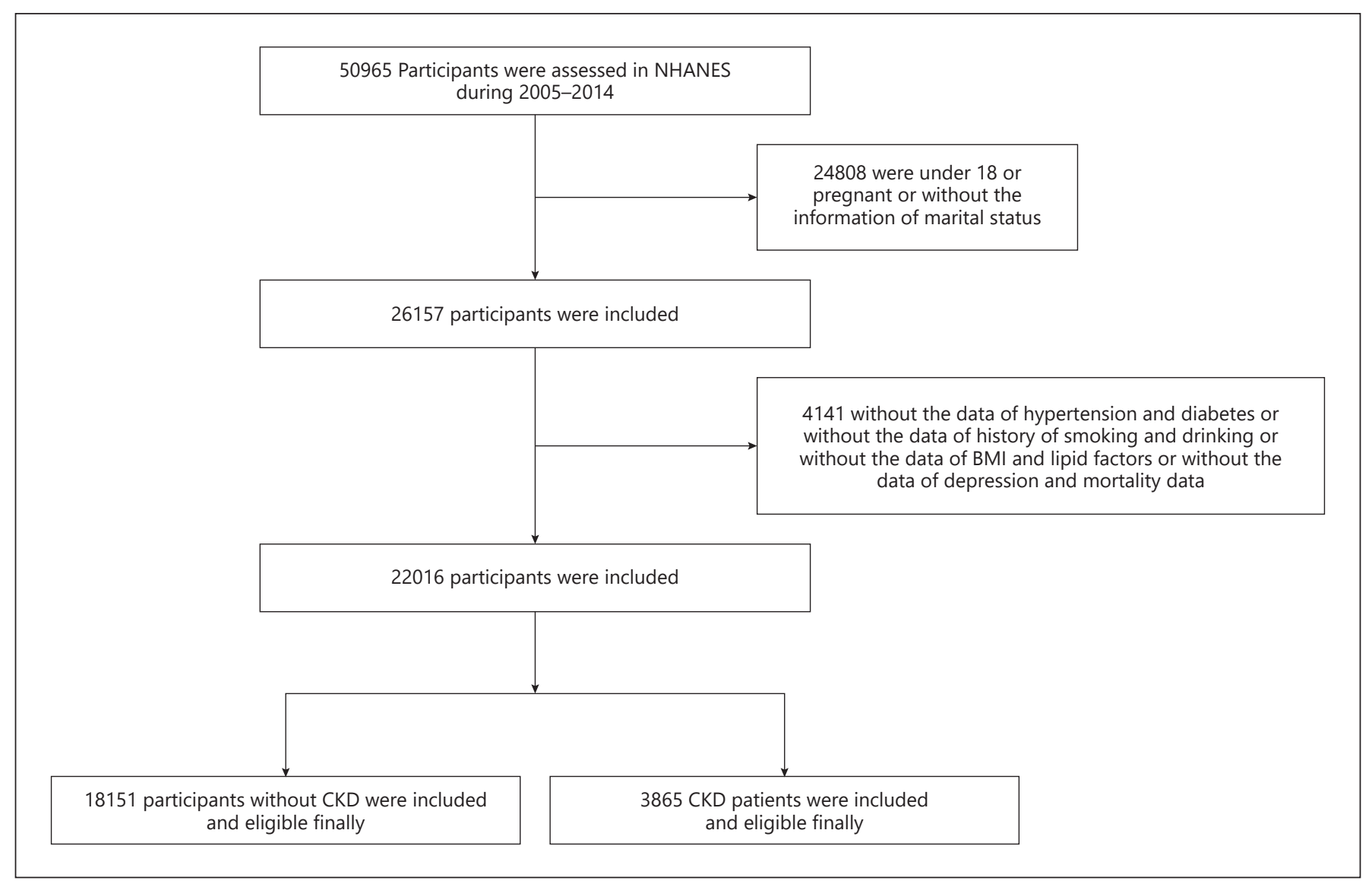

Fig. 1. The screening process of this study.

Marital status is one of the most important social factors of people's lives, which affects various aspects of ones' life, especially mental health [7]. A previous study showed that married people have better mental health than those who are single, widowed, separated, and divorced [8]. On the other hand, it is reported that $25 \%$ of patients with CKD had depression, which is 4 times higher than the prevalence in the general population [9]. However, few studies showed whether marital status effects on the depression of CKD patients.

Besides the mental health, marital status may have an influence on the mortality of general population as well [10]. It is well known to public that patients with CKD have a higher mortality risk than the general population, and the risk of mortality increased with the progression of CKD [11]. Meanwhile, the mortality of CKD was deeply related to medical treatment [12] and social support [13]. Marital status has often been regarded as a marker of social support, and also entails more economic resources, social support [14]. Thus, married people may have a higher quality of life, healthier lifestyle, and behaviors [15] and better medical treatment [16] than the unmarried. However, whether the marital status has influence on mortality of CKD patients is unknown.

Relatively little is known about whether the marital status has effect on depression and mortality of patients with CKD. We thus conducted a study including more than 3,000 patients from National Health and Nutrition Examination Survey (NHANES) data from 2005 to 2014 to assess the effect of marital status on depression and mortality in CKD.

\section{Methods}

\section{Participants}

We performed an analysis of the NHANES database. The NHANES is a periodic survey conducted by the National Center for Health Statistics (NCHS) of the Centers for Disease Control and Prevention (CDC). NCHS performed the data accumulation with approval from the NCHS Ethics Review Board (protocol 
\#2005-06; protocol \#2011-17), and all participants provided written informed consent. We used data from 2005 to 2014 (50,965 people). We restricted our analysis to nonpregnant individuals $>18$ years of age with marital status (26,157 subjects) and excluded from our analysis participants with missing information on hypertension, diabetes, history of smoke and drink, BMI, lipid markers, depression score, and information of mortality (4,141 subjects).18,151 participants without CKD were included in our analysis. In addition, 3,865 patients with $\mathrm{CKD}$ [defined as an estimated glomerular filtration rate $(\mathrm{eGFR})<60 \mathrm{~mL} / \mathrm{min} / 1.73 \mathrm{~m}^{2}$ (using the CKD Epidemiology Collaboration equation) [17]and/or a urinary albumin: Cr ratio $>30 \mathrm{mg} / \mathrm{g}$ ] in our analysis finally. See Figure 1 for detailed information.

\section{Measures}

Marital Status

Marital status was categorized into married, widowed, divorced, separated, never married, living with a partner, refused, and do not know in the primary file of NHANES. In this study, the people of married and living with partner groups were considered as married ones, and people of the widowed group, divorced group, separated group, and the never-married group were considered as unmarried ones.

\section{Depression Outcomes}

Participants were assessed for depression based upon their selfratings on a PHQ-9 questionnaire for symptoms within the prior 2 weeks [18]. This questionnaire is widely used to assess the prevalence and severity of depressive symptoms because it is valid and reliable [19]. Nine questions are scored on a scale of $0-3$ for each frequency question of how often the symptom arose, the zero represents not at all, 1 represents several days, 2 represents more than half the days, and 3 represents to nearly all days. The sum of all 9 questions was used as a quantitative measure of depression along with the cutoff of $\geq 10$ as applied elsewhere [20].

\section{Covariates}

Covariates used in the adjusted analyses were age, sex, race (Mexican American, other Hispanic, non-Hispanic white, nonHispanic black and other), citizen living (yes or no), education level (high school graduate, some college or associate's degree, and college graduate and above), and category of income (low, middle, and high), hypertension (yes, prehypertension, and no), diabetes (yes, prediabetes, and no), physical activity (vigorous, moderate, and none), alcohol drinking status (current drinker, past drinker, and never drinker), smoking status (never smoker, current smoker, or former smoker), category of BMI (obese, overweight, normal weight, and underweight), eGFR $\left(\mathrm{mL} / \mathrm{min} / 1.73 \mathrm{~m}^{2}\right)$, high-density lipoprotein cholesterol (HDL-c) (mmol/L), total cholesterol (TC) $(\mathrm{mmol} / \mathrm{L})$, triglyceride $(\mathrm{TG})(\mathrm{mmol} / \mathrm{L})$, and uric acid $(\mathrm{mmol} / \mathrm{L})$.

The income was classified by the family monthly poverty level index, $<1.30$ referring to as low income, $1.30-1.85$ referring to as middle income, and $>1.85$ referring to as high income. Hypertension was defined as systolic blood pressure (BP) $\geq 140 \mathrm{~mm} \mathrm{Hg}$ or diastolic $\mathrm{BP} \geq 90 \mathrm{~mm} \mathrm{Hg}$ or used antihypertensive medications before the measurement. Prehypertension was defined as a systolic BP between 120 and $129 \mathrm{~mm} \mathrm{Hg}$ or diastolic BP of $80-89 \mathrm{~mm} \mathrm{Hg}$ [21]. Diabetes was defined as a fasting blood glucose concentration $\geq 7 \mathrm{mmol} / \mathrm{L}$, or treatment with insulin or any oral hypoglycemic agent. Participants with fasting blood glucose concentration of
5.6-6.9 $\mathrm{mmol} / \mathrm{L}$ were considered as prediabetes [22]. The BMI was sorted as 4 groups, obese $\left(\geq 25.0 \mathrm{~kg} / \mathrm{m}^{2}\right)$, overweight $(23.0-24.9 \mathrm{~kg} /$ $\mathrm{m}^{2}$ ), normal weight $\left(18.5-22.9 \mathrm{~kg} / \mathrm{m}^{2}\right)$, and underweight $(<18.5$ $\left.\mathrm{kg} / \mathrm{m}^{2}\right)$.

\section{Mortality}

The primary outcome was time to death. Mortality status was determined by NHANES-linked National Death Index public access files through December 31, 2015.

\section{Statistical Analysis}

All calculations took into account the complex survey design of the NHANES database and were analyzed according to the CDC analytic recommendations [23]. Standard description statistics were reported for each marital status group, median and quartile for numerical variables, and percent $(n)$ for categorical variables. Subgroups were grouped by sex, educational level, income, and eGFR with the cutoff of $60 \mathrm{~mL} / \mathrm{min} / 1.73 \mathrm{~m}^{2}$. Since the depression score was nonnormal distribution, the nonparametric test was used to compare the value of depression score between different marital statuses in the different subgroups. The associations of marital status and renal function with depression outcomes were assessed using logistic regression for depression defined by depression sum score $\geq 10$. Three models were calculated, model 1 was nonadjusted, model 2 adjusted for age, sex, race/ethnicity, citizen living, education level, and category of income, and model 3 adjusted for previously mentioned variables plus hypertension, diabetes, physical activity, alcohol consumption, smoking status, BMI, eGFR, HDL-c, TC, TG, and uric acid. Cox proportional hazard models were performed to assess the association between marital status and all-cause mortality, model 1 was nonadjusted, model 2 adjusted for age, sex, race/ethnicity, citizen living, education level, and category of income, and model 3 adjusted for previously mentioned variables plus hypertension, diabetes, physical activity, alcohol consumption, smoking status, BMI, eGFR, HDL-c, TC, TG, uric acid, and depression score. A two-sided $p$ value $<0.05$ was considered statistically significant. Analyses were performed using SPSS software (version 25.0 for Windows; SPSS, Chicago, IL, USA). And the survival curves of CKD patients were performed by GraphPad Prism 6.

\section{Result}

\section{Description of CKD Patients}

The median age of CKD patients was 67 (quartile 5478) years old, and $48.0 \%$ were male. $57.0 \%$ of patients' educational level was high school graduate or less. Meanwhile, $47.5 \%$ of them were high-income group. There were total of 2,092 (54\%) married ones in CKD patients. Compared with married ones, unmarried ones were more likely to be older, female, nonHispanic black, citizen living, lower educational level, lower income, hypertension, nondiabetes, less physical activity, noncurrent alcohol drinker, current smoker, and less obese. Meanwhile, unmarried ones had a higher value of HDL-C and TC and lower value of TG and UC than married ones (Table 1). 
Table 1. Baseline characteristics of the CKD population according to marriage status

\begin{tabular}{|c|c|c|c|c|}
\hline & $\begin{array}{l}\text { All } \\
N=3,865\end{array}$ & $\begin{array}{l}\text { Married } \\
N=2,092\end{array}$ & $\begin{array}{l}\text { Unmarried } \\
N=1,773\end{array}$ & $p$ value \\
\hline Age, years & $67(54-78)$ & $66(53-76)$ & $69(55-80)$ & $<0.001$ \\
\hline \multicolumn{5}{|l|}{ Gender, $N(\%)$} \\
\hline Men & $1,856(48.0)$ & $1,225(66.0)$ & $631(34.0)$ & \multirow[t]{2}{*}{$<0.001$} \\
\hline Women & $2,009(52.0)$ & $867(43.2)$ & $1,142(56.8)$ & \\
\hline \multicolumn{5}{|l|}{ Race/ethnicity, $N(\%)$} \\
\hline Mexican American & $474(12.3)$ & $278(13.3)$ & $196(11.1)$ & \multirow[t]{5}{*}{0.001} \\
\hline Other Hispanic & $293(7.6)$ & $159(7.8)$ & $134(7.6)$ & \\
\hline Non-Hispanic white & $2,015(52.1)$ & $1,152(55.1)$ & $863(48.7)$ & \\
\hline Non-Hispanic black & $863(22.3)$ & $362(17.3)$ & $501(28.3)$ & \\
\hline Other race - including multiracial & $220(5.7)$ & $141(6.7)$ & $79(4.5)$ & \\
\hline \multicolumn{5}{|l|}{ Citizen living, $N(\%)$} \\
\hline Yes & $3,554(92.0)$ & $1,895(90.6)$ & $1,659(93.6)$ & \multirow[t]{2}{*}{0.001} \\
\hline No & $311(7.7)$ & $198(9.4)$ & $113(6.4)$ & \\
\hline \multicolumn{5}{|l|}{ Education, $N(\%)$} \\
\hline High school graduate or less & $2,204(57.0)$ & $1,120(53.5)$ & $1,084(61.1)$ & \multirow[t]{3}{*}{$<0.001$} \\
\hline College & $1,008(26.1)$ & $540(25.8)$ & $468(26.4)$ & \\
\hline More than college & $653(16.9)$ & $432(20.7)$ & $221(12.5)$ & \\
\hline \multicolumn{5}{|l|}{ Category of income, $N(\%)$} \\
\hline Low & $1,388(35.9)$ & $583(27.9)$ & $805(45.6)$ & \multirow[t]{3}{*}{$<0.001$} \\
\hline Middle & $641(16.6)$ & $343(16.4)$ & $298(16.8)$ & \\
\hline High & $1,836(47.5)$ & $1,166(55.7)$ & $670(37.8)$ & \\
\hline \multicolumn{5}{|l|}{ Hypertension, $N(\%)$} \\
\hline Yes & $2,793(2,793)$ & $1,474(70.5)$ & $1,319(74.4)$ & \multirow[t]{3}{*}{0.010} \\
\hline Prehypertension & $537(537)$ & $309(14.8)$ & $228(12.9)$ & \\
\hline No & $535(535)$ & $309(14.8)$ & $226(12.7)$ & \\
\hline \multicolumn{5}{|l|}{ Diabetes, $N(\%)$} \\
\hline Yes & $1,318(34.1)$ & $721(34.5)$ & $597(33.7)$ & \multirow[t]{3}{*}{0.384} \\
\hline Prediabetes & $875(22.6)$ & $482(23.0)$ & $393(22.2)$ & \\
\hline No & $1,672(43.3)$ & $889(42.5)$ & $783(44.2)$ & \\
\hline \multicolumn{5}{|l|}{ Physical activity, $N(\%)$} \\
\hline Vigorous & 737 (19.1) & $448(21.4)$ & $289(16.3)$ & \multirow[t]{3}{*}{$<0.001$} \\
\hline Moderate & $1,413(36.6)$ & $772(36.9)$ & $641(36.2)$ & \\
\hline None & $1,715(44.4)$ & $872(41.7)$ & $843(47.5)$ & \\
\hline \multicolumn{5}{|l|}{ Alcohol consumption, $N(\%)$} \\
\hline Current drinker & $2,187(56.6)$ & $1,241(59.3)$ & $946(53.4)$ & \multirow[t]{3}{*}{0.001} \\
\hline Past drinker & $688(17.8)$ & $342(16.3)$ & $346(19.5)$ & \\
\hline Never & $990(25.6)$ & $509(24.3)$ & $481(27.1)$ & \\
\hline \multicolumn{5}{|l|}{ Smoking status, $N(\%)$} \\
\hline Current smoker & $662(17.1)$ & $319(15.2)$ & $343(19.3)$ & \multirow[t]{3}{*}{0.057} \\
\hline Past smoker & $1,402(36.3)$ & $796(38.0)$ & $606(34.2)$ & \\
\hline Never & $1,800(46.6)$ & $976(46.7)$ & $824(46.5)$ & \\
\hline \multicolumn{5}{|l|}{ BMI, $\mathrm{kg} / \mathrm{m}^{2}$} \\
\hline Obese $\left(\geq 25.0 \mathrm{~kg} / \mathrm{m}^{2}\right)$ & $2,902(75.1)$ & $1,601(76.5)$ & $1,301(73.4)$ & 0.001 \\
\hline Overweight $\left(23.0-24.9 \mathrm{~kg} / \mathrm{m}^{2}\right)$ & $400(10.3)$ & $226(10.8)$ & $174(9.8)$ & \\
\hline Normal weight $\left(18.5-22.9 \mathrm{~kg} / \mathrm{m}^{2}\right)$ & $486(12.6)$ & $226(10.8)$ & $252(14.2)$ & \\
\hline Underweight $\left(<18.5 \mathrm{~kg} / \mathrm{m}^{2}\right)$ & $77(2.0)$ & $31(1.5)$ & $46(2.6)$ & \\
\hline $\mathrm{eGFR}, \mathrm{mL} / \mathrm{min} / 1.73 \mathrm{~m}^{2}$ & $59(49-92)$ & $59(50-92)$ & $59(48-92)$ & 0.272 \\
\hline $\mathrm{HDL}-\mathrm{c}, \mathrm{mmol} / \mathrm{L}$ & $1.3(1.1-1.6)$ & $1.2(1.0-1.5)$ & $1.3(1.1-1.6)$ & $<0.001$ \\
\hline $\mathrm{TC}, \mathrm{mmol} / \mathrm{L}$ & $4.9(4.2-5.7)$ & $4.8(4.1-5.6)$ & $4.9(4.2-5.8)$ & 0.004 \\
\hline $\mathrm{TG}, \mathrm{mmol} / \mathrm{L}$ & $1.6(1.0-2.4)$ & $1.6(1.1-2.5)$ & $1.5(1.0-2.3)$ & $<0.001$ \\
\hline Uric acid, $\mathrm{mmol} / \mathrm{L}$ & $357(292-422)$ & $357(297-428)$ & $351(286-422)$ & 0.004 \\
\hline
\end{tabular}

Values for categorical variables are given as count (percentage); values for continuous variables are given as median (interquartile range). eGFR, estimated glomerular filtration rate; HDL-c, high-density lipoprotein cholesterol; TC, total cholesterol; TG, triglyceride. 
Table 2. The depression score of CKD patients according to gender, eGFR, education level, and income

\begin{tabular}{|c|c|c|c|c|c|}
\hline & \multirow[t]{2}{*}{$N(\%)$} & \multicolumn{3}{|c|}{ All patients, $N=3,865$} & \multirow[t]{2}{*}{$p$ value } \\
\hline & & all & married & unmarried & \\
\hline All & $3,865(100.0)$ & $2.0(0.0-5.0)$ & $2.0(0.0-4.0)$ & $2.0(0.0-6.0)$ & $<0.001$ \\
\hline \multicolumn{6}{|l|}{ Gender } \\
\hline Men & $1,856(48.0)$ & $1.0(0.0-4.0)$ & $1.0(0.0-4.0)$ & $2.0(0.0-5.0)$ & 0.001 \\
\hline Women & $2,009(52.0)$ & $2.0(0.5-6.0)$ & $2.0(0.0-5.0)$ & $3.0(1.0-6.0)$ & 0.009 \\
\hline \multicolumn{6}{|l|}{ Category of education level } \\
\hline High school graduate or less & $2,204(57.0)$ & $2.0(0.0-6.0)$ & $2.0(0.0-5.0)$ & $3.0(0.0-7.0)$ & $<0.001$ \\
\hline College & $1,008(26.1)$ & $2.0(0.0-5.0)$ & $2.0(0.0-4.0)$ & $2.0(0.0-5.0)$ & 0.020 \\
\hline More than college & $653(16.9)$ & $1.0(0.0-3.0)$ & $1.0(0.0-3.0)$ & $2.0(0.0-5.0)$ & $<0.001$ \\
\hline \multicolumn{6}{|l|}{ Category of income } \\
\hline Low & $1,388(35.9)$ & $3.0(0.0-7.0)$ & $2.0(0.0-7.0)$ & $3.0(0.0-8.0)$ & 0.039 \\
\hline Middle & $641(16.6)$ & $2.0(0.0-5.0)$ & $2.0(0.0-5.0)$ & $2.0(0.0-6.0)$ & 0.019 \\
\hline High & $1,836(47.5)$ & $1.0(0.0-4.0)$ & $1.0(0.0-3.0)$ & $2.0(0.0-4.0)$ & 0.001 \\
\hline \multicolumn{6}{|l|}{ Category of eGFR } \\
\hline $\mathrm{eGFR}>60 \mathrm{~mL} / \mathrm{min} / 1.73 \mathrm{~m}^{2}$ & $1,893(48.98)$ & $2.0(0.0-6.0)$ & $2.0(0.0-5.0)$ & $2.0(0.0-6.0)$ & $<0.001$ \\
\hline $\mathrm{eGFR}<60 \mathrm{~mL} / \mathrm{min} / 1.73 \mathrm{~m}^{2}$ & $1,972(51.02)$ & $2.0(0.0-5.0)$ & $1.0(0.0-4.0)$ & $2.0(0.0-6.0)$ & $<0.001$ \\
\hline
\end{tabular}

Values for categorical variables are given as count (percentage); values for continuous variables are given as median (interquartile range). Participants with depression score $\geq 10$ were defined as having depression. eGFR, estimated glomerular filtration rate.

\section{The Situation of Depression among CKD Patients}

The percentage of depression in CKD patients was $10.9 \%$, which was higher than $8.8 \%$ in normal population (see online suppl. Table 1; for all online suppl. material, see www.karger.com/doi/10.1159/000515440). The depression score of CKD patients according to marital status is presented in Table 2. The median of depression score was 2.0 (quartile $0.0-5.0$ ) in total CKD patients. The depression sum scores for unmarried ones were higher than married ones in total. Furthermore, each subgroup showed the similar result like general CKD patients. Table 3 showed the results of the binary logistic models of depression and married status. In CKD patients, unmarried ones showed a higher risk to have depression than married ones $(\mathrm{OR}=1.26,95 \% \mathrm{CI}$ : 1.01-1.57). There was also a significant association between marital status and depression in some subgroups of CKD patients. Unmarried male patients with CKD were more likely to have depression than married ones (OR $=1.45,95 \% \mathrm{CI}: 1.02-2.06)$, while the female group did not have this similar result. Meanwhile, in participants with more than college educational level, unmarried was significantly associated with an increased risk of depression ( $\mathrm{OR}=12.4$, 95\% CI: 3.75-41.02). However, there was no relationship between marital status and depression in other educational level groups. At the same time, none subgroup grouped by eGFR or income showed significant association between depression and marital status.

\section{Marital Status and Mortality in CKD Patients}

There were total 802 (20.8\%) deaths among CKD patients. Figure 2 showed that the cumulative survival rate in unmarried ones was significantly lower than that married ones $(p<0.001)$. The results of cox proportional hazards models to assess the association between marital status and all-cause mortality are shown in Table 4. Among patients with CKD, there was a significant difference of all-cause mortality between patients with different marital statuses. Moreover, marital status was significant associated with all-cause mortality in some subgroups. Unmarried male patients had a threat to death than married ones (HR $=1.64,95 \% \mathrm{CI}: 1.35-2.00)$, while there was no significant relationship between marital status and mortality in the female patients. In the subgroup of participants with high school graduate or less educational level and more than college educational level, marriage had a protective effect against death $(\mathrm{HR}=1.46,95 \% \mathrm{CI}: 1.20$ 1.77 and $\mathrm{HR}=1.62,95 \% \mathrm{CI}: 1.01-2.60$, respectively). However, there was no significant effect of marital status on death in other group of different education. Meanwhile, the middle-income and high-income group also 
Table 3. The association of marriage status and depression in the whole cohort and according to gender, eGFR, education level, and income

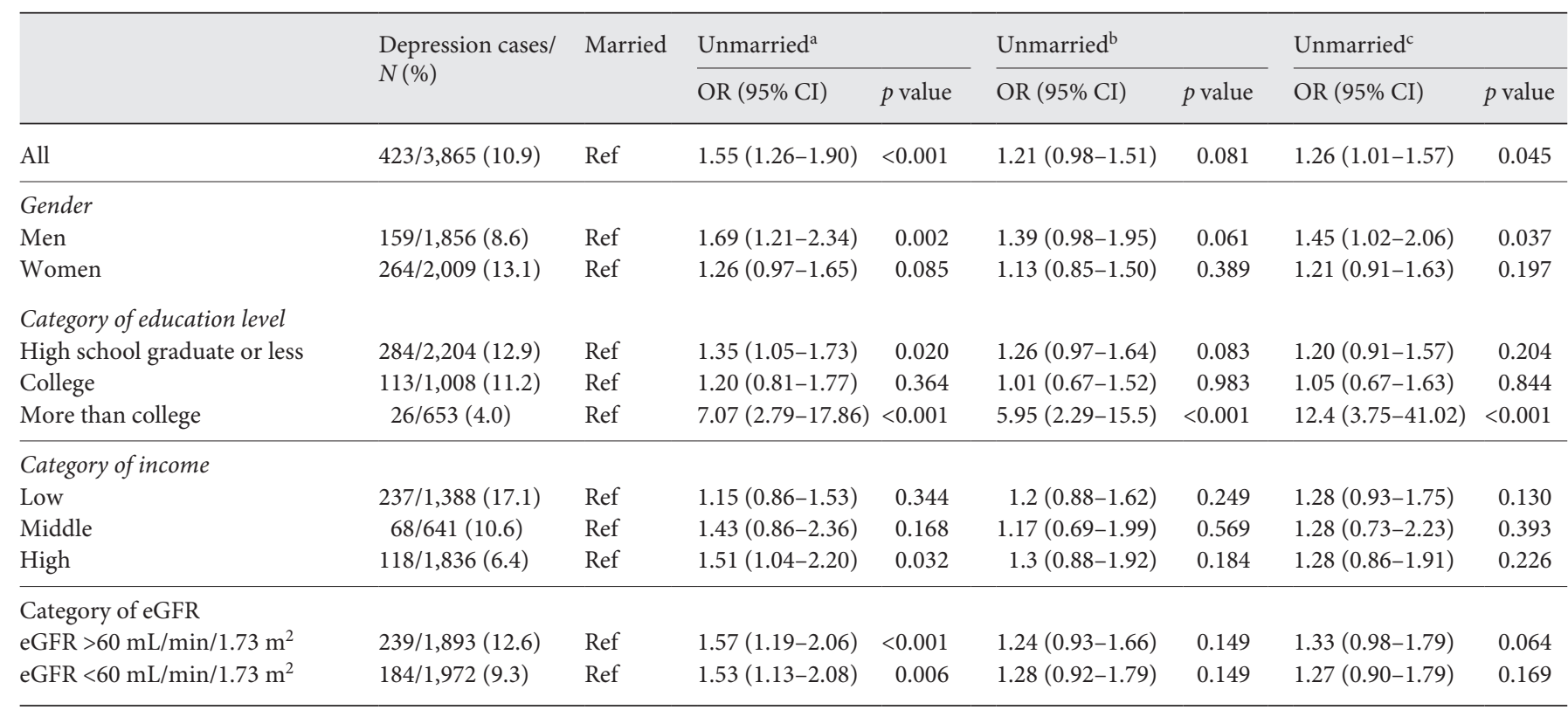

Ref, reference; eGFR, estimated glomerular filtration rate; HDL-c, high-density lipoprotein cholesterol; TC, total cholesterol; TG, triglyceride. Participants with depression score $\geq 10$ were defined as having depression. ${ }^{a}$ Nonadjusted. ${ }^{b}$ Adjusted for age, sex, race/ethnicity, citizen living, education level, and category of income. ${ }^{c}$ Additionally adjusted for hypertension, diabetes, physical activity, alcohol consumption, smoking status, BMI, eGFR, HDL-c, TC, TG, and uric acid.

Table 4. The association of marriage status and mortality in the whole cohort and according to gender, eGFR, education level, and income

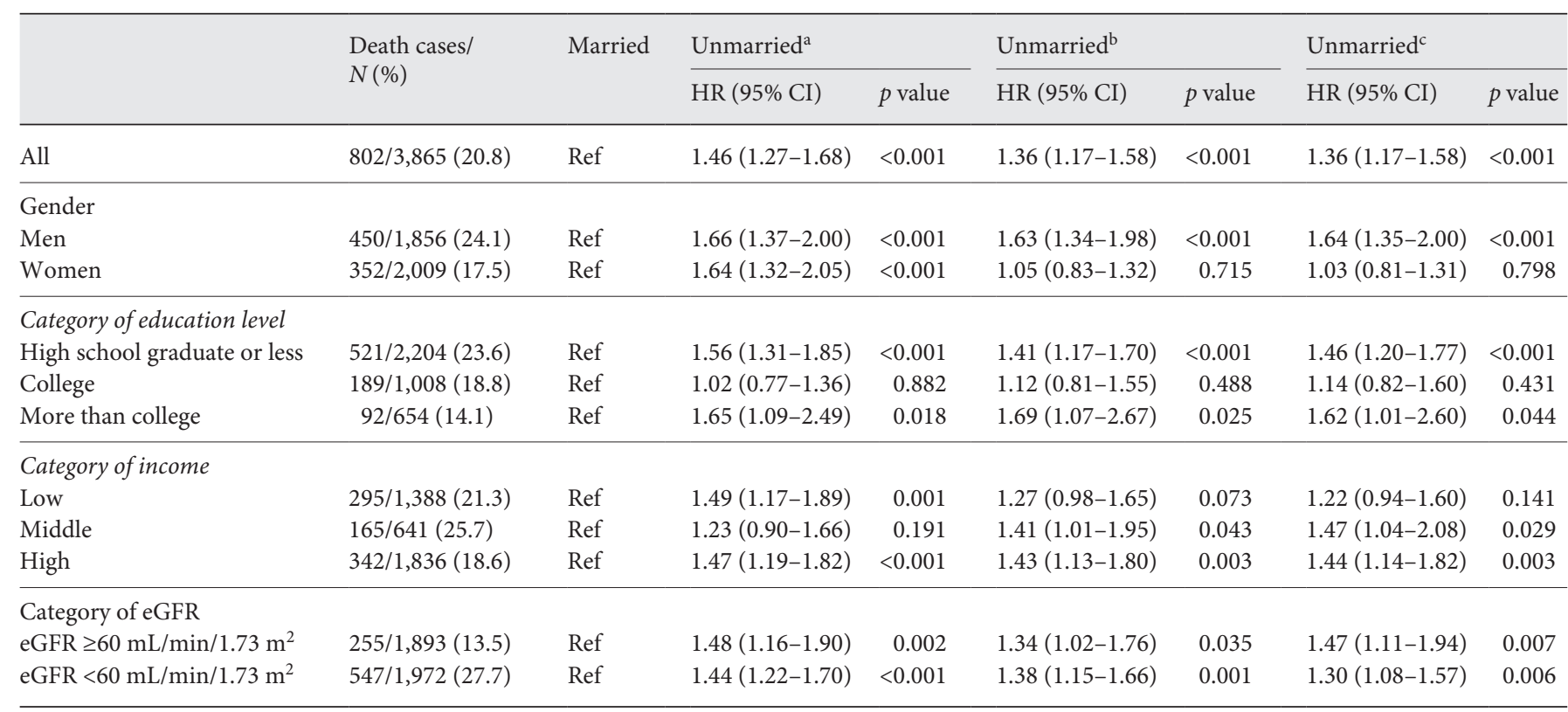

Ref, reference; eGFR, estimated glomerular filtration rate; HDL-c, high-density lipoprotein cholesterol; TC, total cholesterol; TG, triglyceride. a Nonadjusted. ${ }^{b}$ Adjusted for age, sex, race/ethnicity, citizen living, education level, and category of income. ${ }^{c}$ Additionally adjusted for hypertension, diabetes, physical activity, alcohol consumption, smoking status, BMI, eGFR, HDL-c, TC, TG, uric acid, and whether depression. 
Fig. 2. Survival curve for patients with CKD depending on marital status.

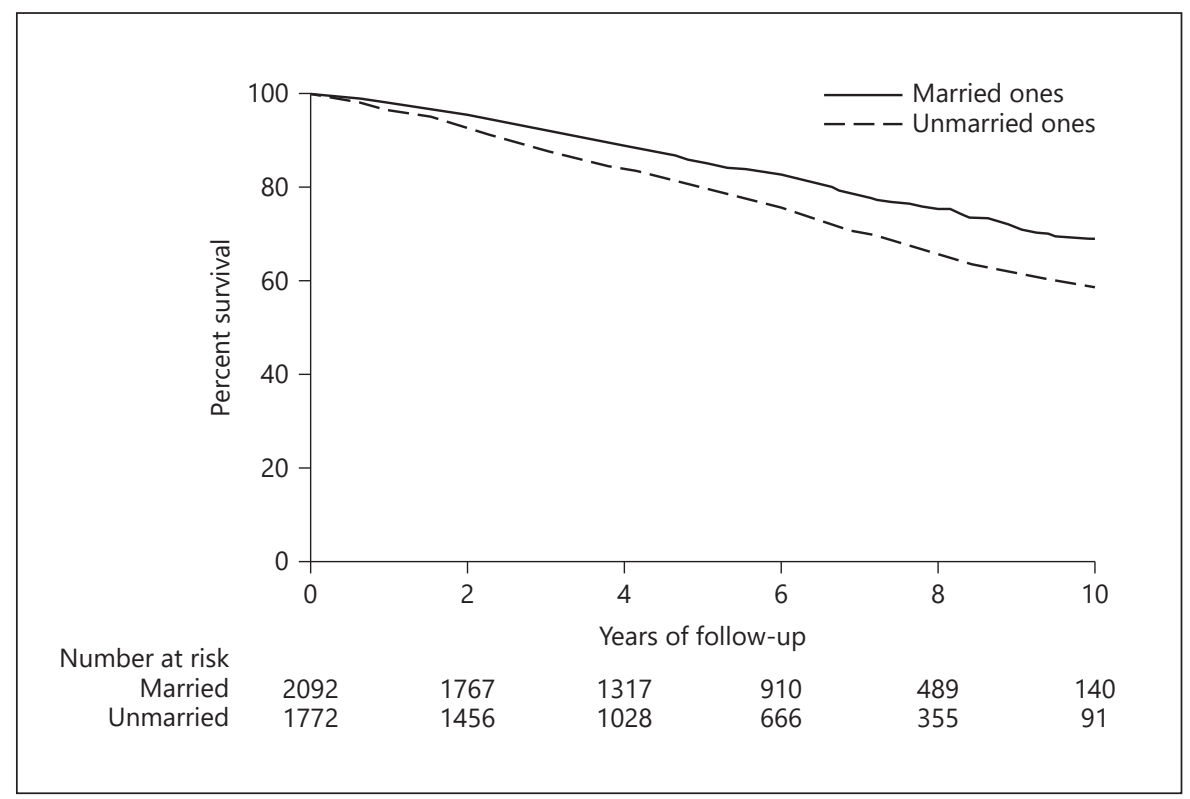

had a significant association between all-cause mortality and marital status, unmarried ones showed a higher risk to death than married ones ( $\mathrm{HR}=1.47,95 \% \mathrm{CI}$ : $1.04-$ 2.08; HR $=1.44,95 \%$ CI: 1.14-1.82), while the low-income group did not show this result. Both subgroups grouped by eGFR showed a significant association between all-cause mortality and marital status.

\section{Discussion}

Our study showed that there was an association between marital status and depression among patients with CKD. Unmarried ones were more likely to have depression than married ones in CKD patients, especially in men, patients with more than college education level. Besides, unmarried ones showed a higher risk of all-cause mortality among CKD patients and some subgroups, including males, patients with high school graduates or less educational level, and higher income group, for example.

This study showed that CKD patients had worse situation of depression than non-CKD patients, which was consistent with previous study [11]. CKD not only triggers major challenges in regard to health but also causes enormous economic losses [24]. Lots of factors lead to this result, including biological factors, psychological factors, and sociodemographic factors [25]. Additionally, recurrent symptoms, life-long treatment, diet, and fluid re- striction of CKD increase the risk of depression among CKD patients [26].

Married ones had lower depression scores and were less likely to have depression than unmarried ones among patients with CKD, which implied that the situation of depression in married ones was better than unmarried ones in this study. The positive role of marriage in the quality of life had been reported in other study [27]. That is, married ones had a higher quality of life than with unmarried ones because of the social support [28], including family income, which might protect people from depression. Furthermore, the mental support from partners or families helps patients release or share the pain and the depression caused by the disease, which partly explained that married ones had healthier mental health [29]. Therefore, these advantages may improve the self-rated quality of life and further help CKD patients to deal with the situation of depression [30].

The influence of marriage on depression was different in different CKD patients [31]. Our study indicated that male CKD patients benefit more from marriage than female patients to avoid having depression, which was consistent with findings in other studies about general people [32]. Females have larger and stronger social support networks than men [33], and men often told that their wives were their chief source of social support, which may partly explain why single, widowed, and divorced males are more likely to have depression than married ones [34]. But the mecha- 
nism of sex difference in marital status affection among CKD patients is not clear now [35], which needs further studies. Our study also showed that unmarried ones had a higher risk to have depression than married ones among CKD patients with more than college education level. A previous study showed that highly educated people paid more attention to mental health than other people [36], thus these participants with CKD were more likely to look for more social support to overcome the negative thoughts during the period of illness [37]. As marriage plays an important role of social support mentioned before [28], this may partly explain this result.

This study showed marital status had a great effect on the mortality of CKD patients as well. As a partner can share the emotional burden and provide appropriate social support [38], it was not surprise to find this result. Meanwhile, a partner can also help you realize the disease earlier [39], which is important to decrease the mortality rate of a disease. The protective effect of marriage in all-cause mortality among male patients with CKD was found in this study, which was compatible with previous researches among the common population [40]. There are several potential reasons for this phenomenon. First, males may get more mental support from marriage than females [41]. Second, some bad life habits, such as smoking and drinking, can be strongly impacted by marriage [42]. Since males tend to have more bad habits than females have [43], males may benefit more than females from the lifestyle change caused by marriage. Our study also found that among patients with school graduate or less educational level and more than college educational level, there was a significant beneficial influence of marriage in all-cause mortality. Since patients with lower educational level may have less knowledge of CKD and lower compliance to doctors [44], they may get more reminders than others from partner to have a regular doctors' office visiting [45]. Hence, this may partly explain what we found in this study. The patients with more than college educational level benefit from marriage have mentioned before, which may also prevent patients from death as well. Similarly, marriage may confer a protective effect regarding all-cause mortality in CKD patients with middle and high income. First of all, high income often relates to high pressure, the support from partner or family is much more important to them than other groups [46]. Second, this subgroup had better economic support to receive good medical services than other subgroups, thus the phys- ical condition of patients may play a critical role in the mortality of this group of CKD patients [47]. Previous studies showed that marriage influences the function of the body physiologically, partially through modulating the level of endocrinal hormones which may influence the mortality of CKD [48].

There are several limitations to this study. Frist, marital status is a time-varying covariate, but we only have cross-sectional data and the length of time for participants with a certain marital status could not be getting from the data. Second, the quality of marriage was not presented in that survey, and it may have some influence between marital status and outcomes of this study. Third, we only had data about the self-reported measures of depression, which may have less specificity compared with doctor-diagnosed depression [49]. Last, many covariates were available only at baseline. Therefore, we do not know whether these time-varying covariates have an impact on the mortality of CKD or not. Though these limitations, this study has a large and nationally representative sample, a high follow-up rate, and detailed data of each participant. Meanwhile, we adjusted lots of covariates in this study to explore the independent influence of marital status on depression and mortality of CKD patients.

\section{Conclusion}

On the basis of our findings, marital status has great influence on depression and mortality of CKD patients. Further, studies are still needed to explore the mechanism of how marital status effect CKD patients' mental health and mortality. These researches may help improve mental health and reduce the mortality of CKD patients.

\section{Statement of Ethics}

The NHANES is a periodic survey conducted by the NCHS of the CDC. NCHS performed the data accumulation with approval from the NCHS Ethics Review Board (protocol \#2005-06; protocol \#2011-17), and all participants provided written informed consent.

\section{Conflict of Interest Statement}

The authors have no conflicts of interest to declare. 


\section{Funding Sources}

This work was financially supported by the International (regional) cooperation and exchange projects (NSFC-DFG, Grant No. 81761138041); National Natural Science Foundation of China (Grants 81570667, 81470948, 81670633); Major Research Plan of the National Natural Science Foundation of China (Grant No. 91742204); the National Key R\&D Program of China (Gran2018YFC1314003-1, 2015BAI12B07), and National key research and development program (Grants 2016YFC0906103).

\section{Author Contributions}

Z.W. and Y.C. had full access to all of the data in the study and takes responsibility for the accuracy of the data analysis. S.G., G.X., and Z.W. developed study concept and design. Z.W., N.Z., R.L., Y.C., and K.G. performed the statistical analyses and drafted the manuscript. G.X. and S.G. obtained the funding and supervised the study. Requests for reprints should be addressed to Shu-Wang Ge, PhD, Department of Nephrology, Tongji Hospital, Tongji Medical College, and Huazhong University of Science and Technology, No. 1095 Jiefang Road, Wuhan 430030, China. E-Mail: geshuwang@ tjh.tjmu.edu.cn.

\section{References}

1 Jha V, Garcia-Garcia G, Iseki K, Li Z, Naicker S, Plattner B, et al. Chronic kidney disease: global dimension and perspectives. Lancet. 2013;382(9888):260-72.

2 Saran R, Robinson B, Abbott KC, Agodoa LYC, Bragg-Gresham J, Balkrishnan R, et al. US renal data system 2018 annual data report: epidemiology of kidney disease in the United States. Am J Kidney Dis. 2019;73(3 Suppl 1): A7-A8.

3 Tonelli M, Wiebe N, Guthrie B, James MT, Quan H, Fortin M, et al. Comorbidity as a driver of adverse outcomes in people with chronic kidney disease. Kidney Int. 2015; 88(4):859-66.

4 Chen J, Budoff MJ, Reilly MP, Yang W, Rosas SE, Rahman M, et al. Coronary artery calcification and risk of cardiovascular disease and death among patients with chronic kidney disease. JAMA Cardiol. 2017;2(6):635-43.

5 GBD Chronic Kidney Disease Collaboration. Global, regional, and national burden of chronic kidney disease, 1990-2017: a systematic analysis for the Global Burden of Disease Study 2017. Lancet. 2020;395(10225):70933.

6 Dunkler D, Kohl M, Heinze G, Teo KK, Rosengren A, Pogue J, et al. Modifiable lifestyle and social factors affect chronic kidney disease in high-risk individuals with type 2 diabetes mellitus. Kidney Int. 2015;87(4): 784-91.

7 Bulloch AG, Williams JV, Lavorato DH, Patten SB. The relationship between major depression and marital disruption is bidirectional. Depress Anxiety. 2009;26(12):11727.

8 Jang SN, Kawachi I, Chang J, Boo K, Shin HG, Lee $\mathrm{H}$, et al. Marital status, gender, and depression: analysis of the baseline survey of the Korean longitudinal study of ageing (KLoSA). Soc Sci Med. 2009;69(11):1608-15.

9 Palmer S, Vecchio M, Craig JC, Tonelli M, Johnson DW, Nicolucci A, et al. Prevalence of depression in chronic kidney disease: systematic review and meta-analysis of observational studies. Kidney Int. 2013;84(1):179-91.

10 Franke S, Kulu H. Cause-specific mortality by partnership status: simultaneous analysis us- ing longitudinal data from England and Wales. J Epidemiol Community Health. 2018; 72(9):838-44.

11 Reichel H, Zee J, Tu C, Young E, Pisoni RL, Stengel B, et al. Chronic kidney disease progression and mortality risk profiles in Germany: results from the Chronic Kidney Disease Outcomes and Practice Patterns Study. Nephrol Dial Transplant. 2020;35(5):803-10.

12 Tangri N, Inker LA, Hiebert B, Wong J, Naimark $\mathrm{D}$, Kent $\mathrm{D}$, et al. A dynamic predictive model for progression of CKD. Am J Kidney Dis. 2017;69(4):514-20.

13 Lora CM, Gordon EJ, Sharp LK, Fischer MJ, Gerber BS, Lash JP. Progression of CKD in Hispanics: potential roles of health literacy, acculturation, and social support. Am J Kidney Dis. 2011;58(2):282-90.

14 Lindström M. Social capital, economic conditions, marital status and daily smoking: a population-based study. Public Health. 2010; 124(2):71-7.

15 Cao Y, Krause JS, Saunders LL, Clark JM. Impact of marital status on 20-year subjective well-being trajectories. Top Spinal Cord Inj Rehabil. 2015;21(3):208-17.

16 Merrill RM, Johnson E. Benefits of marriage on relative and conditional relative cancer survival differ between males and females in the USA. J Cancer Surviv. 2017;11(5):578-89.

17 Levey AS, Stevens LA, Schmid CH, Zhang YL, Castro AF 3rd, Feldman HI, et al. A new equation to estimate glomerular filtration rate. Ann Intern Med. 2009;150(9):604-12.

18 Arab L, Guo R, Elashoff D. Lower depression scores among walnut consumers in NHANES. Nutrients. 2019;11(2):275.

19 Kroenke K, Spitzer RL, Williams JB. The PHQ-9: validity of a brief depression severity measure. J Gen Intern Med. 2001;16(9):60613.

20 Manea L, Gilbody S, McMillan D. Optimal cut-off score for diagnosing depression with the patient health questionnaire (PHQ-9): a meta-analysis. CMAJ. 2012;184(3):E191-6.

21 Booth JN, 3rd, Li J, Zhang L, Chen L, Muntner $\mathrm{P}$, Egan $\mathrm{B}$. Trends in prehypertension and hypertension risk factors in US adults: 1999 2012. Hypertension. 2017;70(2):275-84.
22 Khetan AK, Rajagopalan S. Prediabetes. Can J Cardiol. 2018;34(5):615-23.

23 Johnson CL, Paulose-Ram R, Ogden CL, Carroll MD, Kruszon-Moran D, Dohrmann SM, et al. National health and nutrition examination survey: analytic guidelines, 1999-2010. Vital Health Stat 2. 2013(161):1-24.

24 Chiang HH, Livneh H, Yen ML, Li TC, Tsai TY. Prevalence and correlates of depression among chronic kidney disease patients in Taiwan. BMC Nephrol. 2013;14:78.

25 Zalai D, Szeifert L, Novak M. Psychological distress and depression in patients with chronic kidney disease. Semin Dial. 2012; 25(4):428-38.

26 Ahlawat R, Tiwari P, D'Cruz S. Prevalence of depression and its associated factors among patients of chronic kidney disease in a public tertiary care hospital in India: a cross-sectional study. Saudi J Kidney Dis Transpl. 2018; 29(5):1165-73.

27 Han KT, Park EC, Kim JH, Kim SJ, Park S. Is marital status associated with quality of life? Health Qual Life Outcomes. 2014;12:109.

28 Blazer DG. Depression in late life: review and commentary. J Gerontol A Biol Sci Med Sci. 2003;58(3):249-65.

29 Borstelmann NA, Rosenberg SM, Ruddy KJ, Tamimi RM, Gelber S, Schapira L, et al. Partner support and anxiety in young women with breast cancer. Psychooncology. 2015; 24(12):1679-85.

30 Kinariwalla N, Sen A. The psychosocial impact of epilepsy on marriage: a narrative review. Epilepsy Behav. 2016;63:34-41.

31 Tepavcević DK, Pekmezović T, Drulović J. [Quality of life assessment in patients with multiple sclerosis]. Vojnosanit Pregl. 2009; 66(8):645-50.

32 Bulloch AGM, Williams JVA, Lavorato DH, Patten SB. The depression and marital status relationship is modified by both age and gender. J Affect Disord. 2017;223:65-8.

33 Tifferet S. Gender differences in social support on social network sites: a meta-analysis. Cyberpsychol Behav Soc Netw. 2020;23(4):199-209.

34 Tatangelo G, McCabe M, Campbell S, Szoeke C. Gender, marital status and longevity. Maturitas. 2017;100:64-9.
Effect of Marital Status on Chronic

Kidney Disease Patients
Kidney Dis 2021;7:391-400

DOI: $10.1159 / 000515440$ 
35 Salk RH, Hyde JS, Abramson LY. Gender differences in depression in representative national samples: meta-analyses of diagnoses and symptoms. Psychol Bull. 2017;143(8): 783-822.

36 Kurspahić Mujčić A, Mujčić A. The relationship between education and self-reported mental and physical health. Med Glas. 2019; 16(1):102-7.

37 van der Heide I, Wang J, Droomers M, Spreeuwenberg P, Rademakers J, Uiters E. The relationship between health, education, and health literacy: results from the Dutch adult literacy and life skills survey. J Health Commun. 2013;18(Suppl 1):172-84.

38 Goldzweig G, Andritsch E, Hubert A, Brenner B, Walach N, Perry S, et al. Psychological distress among male patients and male spouses: what do oncologists need to know? Ann Oncol. 2010;21(4):877-83.
39 Sharon CE, Sinnamon AJ, Ming ME, Chu EY, Fraker DL, Karakousis GC. Association of marital status with $\mathrm{T}$ stage at presentation and management of early-stage melanoma. JAMA Dermatol. 2018;154(5):574-80.

40 Robards J, Evandrou M, Falkingham J, Vlachantoni A. Marital status, health and mortality. Maturitas. 2012;73(4):295-9.

41 Xie JC, Yang S, Liu XY, Zhao YX. Effect of marital status on survival in glioblastoma multiforme by demographics, education, economic factors, and insurance status. Cancer Med. 2018;7(8):3722-42.

42 Kiecolt-Glaser JK, Newton TL. Marriage and health: his and hers. Psychol Bull. 2001; 127(4):472-503.

43 Varì R, Scazzocchio B, D'Amore A, Giovannini C, Gessani S, Masella R. Gender-related differences in lifestyle may affect health status. Ann Ist Super Sanita. 2016;52(2):15866.

44 Alexopoulos EC, Geitona M. Self-rated health: inequalities and potential determinants. Int J Environ Res Public Health. 2009; 6(9):2456-69.
45 Gomez SL, Hurley S, Canchola AJ, Keegan TH, Cheng I, Murphy JD, et al. Effects of marital status and economic resources on survival after cancer: a population-based study. Cancer. 2016;122(10):1618-25.

46 Pao HT, Chen CC. Decoupling of environmental pressure and economic growth: evidence from high-income and nuclear-dependent countries. Environ Sci Pollut Res Int. 2020;27(5):5192-210.

47 Morishita S, Tsubaki A, Shirai N. Physical function was related to mortality in patients with chronic kidney disease and dialysis. Hemodial Int. 2017;21(4):483-9.

48 Chin B, Murphy ML, Janicki-Deverts D, Cohen S. Marital status as a predictor of diurnal salivary cortisol levels and slopes in a community sample of healthy adults. Psychoneuroendocrinology. 2017;78:68-75.

49 Beck AT, Brown GK, Steer RA, Kuyken W, Grisham J. Psychometric properties of the Beck Self-Esteem Scales. Behav Res Ther. 2001;39(1):115-24 